\title{
Enhancing Performance of Liquid Sample Desorption Electrospray Ionization Mass Spectrometry Using Trap and Capillary Columns
}

\author{
Si Cheng ${ }^{1}$, Jun Wang, ${ }^{1,2}$ Yi Cai, ${ }^{1}$ Joseph A. Loo, ${ }^{3}$ and Hao Chen ${ }^{* 1}$
}

${ }^{1}$ Center for Intelligent Chemical Instrumentation, Department of Chemistry and Biochemistry, Edison Biotechnology Institute, Ohio University, Athens, OH, 45701, USA, Email:

chenh2@ohio.edu

${ }^{2}$ Department of forensic science, Jiangsu Police Institute, Nanjing, Jiang Su, 210031, China, Email: kwangjun@jspi.edu.cn

${ }^{3}$ Department of Chemistry and Biochemistry, Department of Biological Chemistry, David Geffen School of Medicine at UCLA, and UCLA/DOE Institute for Genomics and Proteomics, University of California-Los Angeles, Los Angeles, California 90095, USA, Email: JLoo@chem.ucla.edu

\author{
Prepared for
}

International Journal of Mass Spectrometry 


\begin{abstract}
Desorption electrospray ionization mass spectrometry (DESI-MS) is a recent and important advance in the field that has extensive applications in surface analysis of solid samples but has also been extended to analysis of liquid samples. The liquid sample DESI typically employs a piece of fused silica capillary to transfer liquid sample for ionization. In this study, we present the improvement of liquid sample DESI-MS by replacing the sample transfer silica capillary with a trap column filled with chromatographic stationary phase materials (e.g., C4, C18). This type of trap column/liquid sample DESI can be used for trace analysis of organics and biomolecules such as proteins/peptides (in $\mathrm{nM}$ concentration) in high salt content matrices. Furthermore, when the sample transfer capillary is modified with enzyme covalently bound on its inside capillary wall, fast digestion $(<6 \mathrm{~min})$ of proteins such as phosphoproteins can be achieved and the online digested proteins can be directly ionized using DESI with high sensitivity. The latter is ascribed to the freedom to select favorable spray solvent for the DESI analysis. Our data shows that liquid sample DESI-MS with a modified sample transfer capillary has significantly expanded its utility in bioanalysis.
\end{abstract}

Keywords: Mass spectrometry; desorption electrospray ionization; desalting and enrichment; online enzyme digestion; phosphoprotein. 


\section{Introduction}

Desorption electrospray ionization (DESI), as a representative ambient ionization technique, was introduced in 2004 by Cooks and co-workers as a milestone in the field of mass spectrometry (MS)(1). This technique is used as a rapid analytical tool to provide efficient desorption and ionization of target compounds for mass spectrometric characterization. It has become very successful in the fast analysis of a variety of analytes including pharmaceuticals(2, 3), metabolites $(4,5)$, drugs of abuse $(6,7)$, explosives $(8,9)$, chemical warfare agents(10), and even intact tissues(11). Traditional DESI addresses solid samples deposited onto a surface. In our and other's laboratories, DESI was extended for the analysis of liquid samples (12-16). Analyte ionization by liquid sample DESI occurs via the interaction of the liquid sample with charged droplets generated by the DESI spray and the resulting ions are collected and analyzed by a mass spectrometer. It is useful in directly analyzing samples including large proteins/protein complexes from their native environments $(12,17-22)$. Furthermore, it is possible to use liquid sample DESI-MS for studying fast reaction kinetics in submillisecond time resolution(23) or coupling with liquid chromatography (LC) (24-27), microfluidics (13), and microextraction (28). The combination of DESI with electrochemistry (EC) (29) has shown that liquid DESI-MS can be used to capture transient intermediates (30-32). The coupled EC/DESI-MS (i.e., the combination of EC with DESI-MS) is also useful for the structural analysis of disulfide bondcontaining proteins in either top-down(33) or bottom-up MS approaches(24, 34) and for probing protein 3D-structures and protein-protein interactions in combination with cross-linking chemistry(35).

In liquid sample DESI experiments, a fused silica capillary is employed to transfer liquid sample for ionization. The delivery of liquid sample using the silica capillary overcomes an issue 
that the liquid sample could be blown away by the nebulization gas of DESI if it is directly deposited on a surface, therefore allowing the continuous introduction and ionization of sample to gain continuous signal. In this study, we attempted to further enhance the analytical performance of liquid DESI via either replacing the sample transfer capillary with a trap column filled with C4/C18 material or modifying the sample capillary with enzyme (e.g., trypsin) bound on its inner wall. The former modification would allow sample desalting and enrichment using the trap column, while the latter enables fast on-column protein digestion. Our experimental results show that these improvements enable liquid DESI-MS to analyze trace amount of analytes in complicated matrices and examine proteins via an accelerated shot-gun MS approach.

\section{Materials and Methods}

\subsection{Materials}

C4 and C18 trap columns (1.5 cm in length, $1 \mathrm{~mm}$ ID) were purchased from Optimize Techonologies. Acetic acid (HOAc), formic acid (FA), sodium hydroxide, hydrochloric acid, phosphate buffer (sodium dihydogen phosphte/sodium monohydrogenphosphate), flunitrazepam, tris buffer, sodiumcyanoboro hydride, glutaraldehyde solution, ammonium hydrogen difluoride ((NH $\left.\left.\mathrm{N}_{4} \mathrm{~F}\right) \mathrm{HF}\right)$, (3-aminopropyl)trimethoxysilane (APTES), trypsin from porcine pancreas, GlyPhe-Ser peptide, Tyr-Tyr-Tyr peptide, angiotensin II, insulin from bovine pancreas, ubiquitin from bovine erythrocyte, $\beta$-casein from bovine milk and myoglobin from horse heart were all purchased from Sigma Aldrich (St. Louis, MO, USA). Fused silica capillaries were obtained from Polymicro Technologies (Phoenix, AZ, USA). Methanol, ethanol and acetonitrile (HPLC grade) were from Fisher Scientific (Fair Lawn, NJ). The de-ionized water used for sample preparation was obtained using a Nanopure Diamond Barnstead purification system (Barnstead 
International, Dubuque, IA). A propane microflame torch and Diet Pepsi were purchased from a local Walmart store.

\subsection{Methods}

Experiments were performed using a DECA LCQ ion trap mass spectrometer (Thermo Finnigin) and a quadrupole time-of-flight (Q-TOF; Waters) equipped with a commerical electrospray ionization (ESI) source and a homemade DESI source (described below). The voltage on the DESI sprayer was set at $5 \mathrm{kV}$. Scheme 1a shows the configuration for integrating a trap cartridge column with liquid sample DESI-MS. $5 \mathrm{~mL}$ of test sample in low concentration (either flunitrazepam in Diet Pepsi or proteins/peptides in phosphate buffer) is loaded into the trap column; the column can retain the sample and allow the sample matrix or buffer to be washed away with water. Then an organic-containing solvent is injected to elute the sample out, which can be detected by DESI with a spray solvent of $\mathrm{MeOH} / \mathrm{H}_{2} \mathrm{O} / 1 \% \mathrm{HOAc}$ aimed at the exit surface of the trap column. The nitrogen nebulization gas of DESI was set to 160 psi. For flunitrazepam sample desalting, a C18 trap column was first equilibrated with $1 \mathrm{~mL}$ water, then 5 $\mathrm{mL}$ of $50 \mathrm{nM}$ flunitrazepam in Diet Pepsi was infused to the trap column followed with washing using another $1 \mathrm{~mL}$ of water. Elution was carried out use ACN. A similar process was used for desalting and enrichment of protein/peptide samples. A $200 \mu \mathrm{L}$ wetting solution (ACN/water/TFA, 2/98/0.1\%, by volume) was first introduced to the trap column to balance the C18/C4 trap column. Then $5 \mathrm{~mL}$ of $50 \mathrm{nM}$ angiotensin II or $40 \mathrm{nM}$ insulin in $0.1 \mathrm{M}$ phosphate buffer was introduced to the trap column for trapping. $1 \mathrm{~mL}$ water was injected to remove the phosphate buffer and organic phase (ACN/water, 65/35 by volume) was used to elute the peptide or protein out for DESI-MS analysis. 
Scheme $1 \mathrm{~b}$ displays the configuration for integrating a piece of enzyme-modified fused silica capillary with liquid sample DESI-MS. The enzyme trypsin is immobilized on the inner wall of the silica capillary (modification procedure described below). When protein is infused through the capillary, digestion can be achieved. The resulting peptides can be directly detected by DESI-MS. In this case, the protein sample is infused into the capillary column at $1 \mu \mathrm{L} / \mathrm{min}$ and the DESI spray solvent of $\mathrm{ACN} / \mathrm{H}_{2} \mathrm{O} / 5 \% \mathrm{FA}$ is injected at $1 \mu \mathrm{L} / \mathrm{min}$. The DESI probe capillary tip is in contact with the tip of the modified sample capillary. When the digested protein sample exits from the capillary column, it will merge with the DESI spray solvent. Because the DESI spray solvent is charged to $5 \mathrm{kV}$, the mixed sample solution will be sprayed out. No sheath gas is used for the DESI spray. Because of the freedom to choose a favorable DESI spray solvent (17) regardless of the nature of the digested protein sample, high ionization efficiency can be obtained. Collision induced dissociation (CID) is used for ion structural confirmation in these experiments.

a)

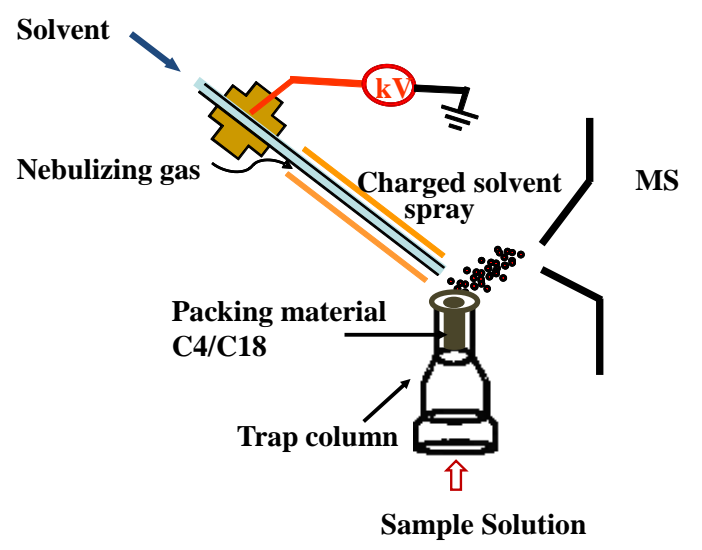

b)

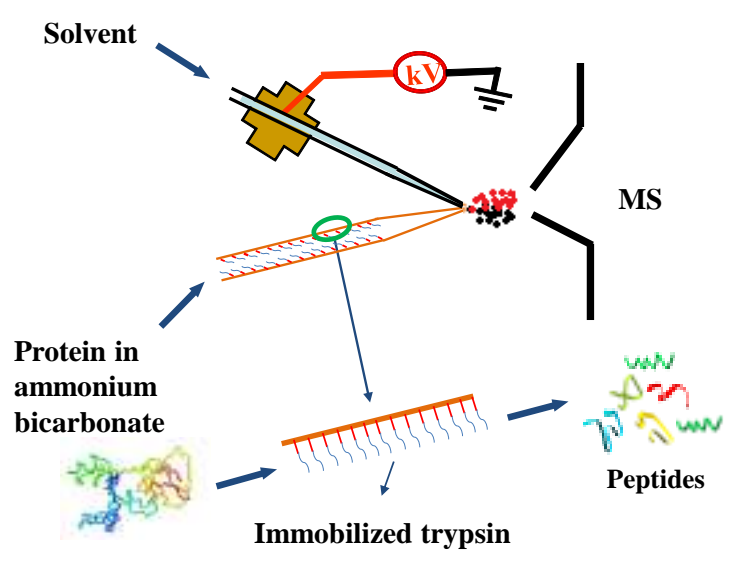

Scheme 1. a) Scheme showing the configuration of trap column/DESI-MS; DESI spray solvent used was $\mathrm{MeOH} / \mathrm{H}_{2} \mathrm{O} / 1 \% \mathrm{HOAc}$. b) Scheme showing the configuration of capillary column/DESI-MS; DESI spray solvent used was $\mathrm{ACN} / \mathrm{H}_{2} \mathrm{O} / 5 \%$ FA. 
Trypsin-immobilized capillary column preparation

Trypsin is immobilized onto a silica capillary following a modified method from the literature (36). A piece of fused silica capillary ( $360 \mu \mathrm{m} \mathrm{OD}, 250 \mu \mathrm{m} \mathrm{ID}, 12 \mathrm{~cm}$ in length) is first flushed with $10 \% \mathrm{NaOH}$ at $5 \mu \mathrm{L} / \mathrm{min}$ for overnight and then flushed with $5 \mathrm{~mL}$ water at 500 $\mu \mathrm{L} / \mathrm{min} .5 \mathrm{~mL}$ of $0.5 \mathrm{M} \mathrm{HCl}$ is introduced into the capillary at $50 \mu \mathrm{L} / \mathrm{min}$ and then the capillary is flushed with $5 \mathrm{~mL}$ water at $500 \mu \mathrm{L} / \mathrm{min}$ for removing the impurities in the silica capillary column. An aqueous solution of saturated ammonium hydrogen difluoride is infused into the capillary at $20 \mu \mathrm{L} / \mathrm{min}$ for inner wall corrosion to increase the inner surface area of the capillary. $2 \mathrm{~mL}$ of APTES is mixed with $1 \mathrm{~mL} 0.25 \%$ ammonia, $20 \mathrm{~mL}$ ethanol and $1 \mathrm{~mL}$ water and then infused into the capillary at $5 \mu \mathrm{L} / \mathrm{min}$ for 10 hours, to react with inner wall surface hydroxyl groups for introducing terminal amino groups. Then the capillary was flushed with glutardialdehyde (30 $\mu \mathrm{L}$ in $5 \mathrm{~mL}$ water) at $3 \mu \mathrm{L} / \mathrm{min}$ for 16 hours at room temperature to effect the Schiff base reaction. Subsequently the capillary is washed with water and dried with argon. $4 \mathrm{mg} / \mathrm{mL}$ trypsin dissolved in water is injected at $3 \mu \mathrm{L} / \mathrm{min}$ into the capillary and covalently bound to the surface, again via the formation of Schiff base with the remaining aldehyde group of glutardialdehyde. Finally $5 \mathrm{mg} / \mathrm{mL}$ sodium cyanoborohydride in water is infused at $3 \mu \mathrm{L} / \min$ to the capillary for reducing the $\mathrm{C}=\mathrm{N}$ double bond. The end of this capillary column is flame heated and pulled to form a tapered tip. The immobilized trypsin column is stored at $4{ }^{\circ} \mathrm{C}$ prior to use for both DESIMS experiments and nano-ESI-MS experiments for comparison.

\section{Results and discussion}

\subsection{Liquid DESI-MS using a trap cartridge column}


First, we examined the performance of liquid DESI-MS when a trap cartridge column was used for sample introduction. Different samples such as drug-of-abuse in drink, proteins/peptides in phosphate buffer were chosen as test samples.

\subsubsection{Detection of drug of abuse in drink}

Flunitrazepam (structure shown in Figure 1a) is a potent sedative and powerful drug for the treatment of insomnia used around the world. At the same time, it is employed in some cases that involve drug facilitated sexual assaults (DFSA) and robberies (37). It is used by predators because of its rapid onset of action (e.g. dosed in drink), hypnotic effect and its ability to cause anterograde amnesia. Because this drug has a very short life time and rapid clearance, the fast and sensitive detection of this drug is desired.

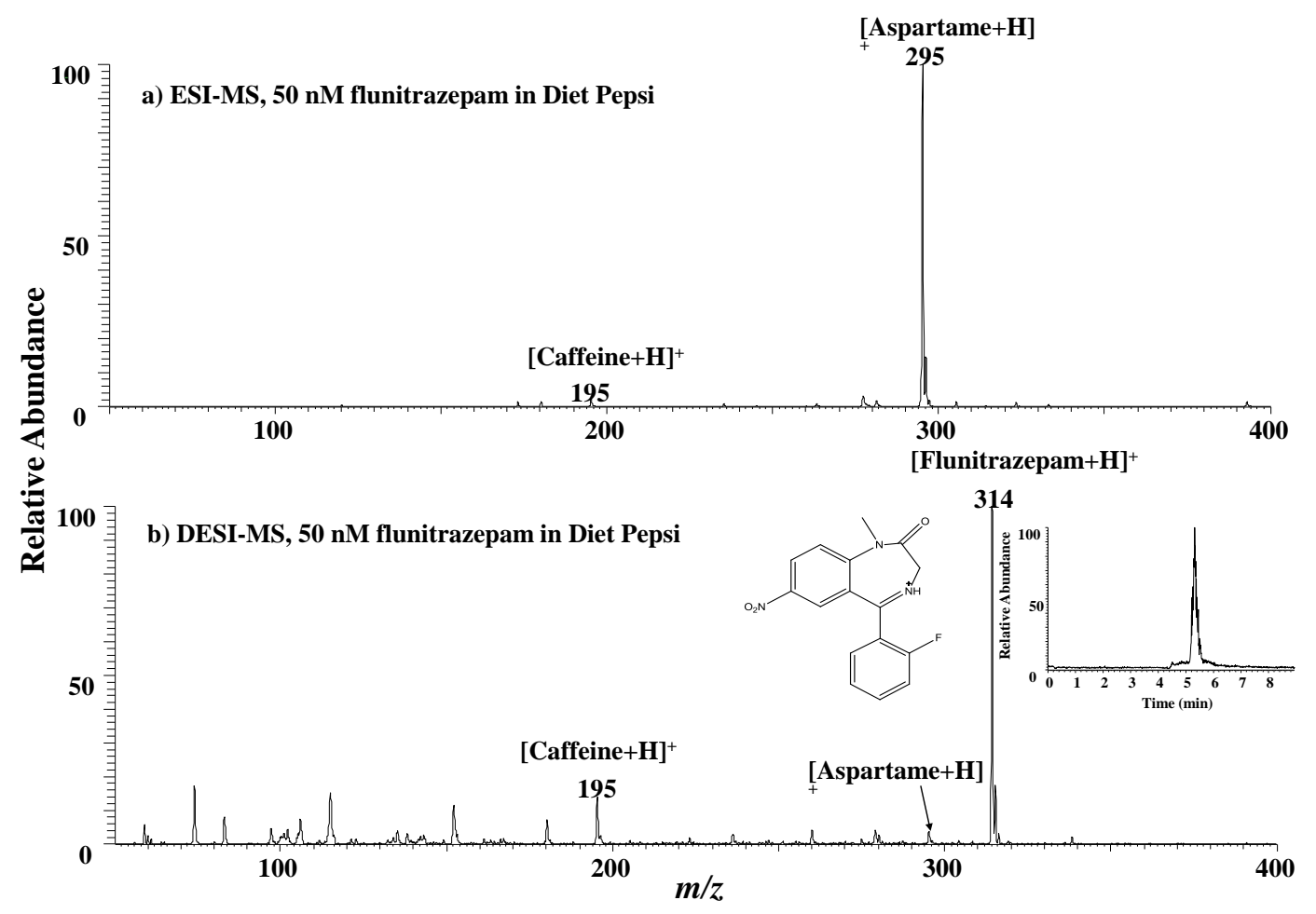

Figure 1 a) ESI-MS spectrum of $50 \mathrm{nM}$ flunitrazepam in Diet Pepsi; b) DESI-MS spectrum of $50 \mathrm{nM}$ flunitrazepam in Diet Pepsi after trap column desalting and enrichment. Figure 1b inset displays the extracted ion chromatogram (EIC) of the ion detected at $\mathrm{m} / \mathrm{z} 314$. 
In our experiment, a low concentration of flunitrazepam (50 nM) in Diet Pepsi was first tested. In the acquired ESI-MS spectrum shown in Figure 1a, no flunitrazepam was detected. Instead, aspartame and caffeine from Diet Pepsi were seen at $\mathrm{m} / z 295$ and $\mathrm{m} / z$ 195, respectively. The failure of detecting flunitrazepam is probably either due to the low concentration of flunitrazepam or the possible matrix effect of the compounds in Diet Pepsi that suppresses the flunitrazepam signal. Interestingly, when $50 \mathrm{nM}$ flunitrazepam in Diet Pepsi (5 mL, total amount $0.25 \mathrm{nmol}$ ) was trapped by a C18 trap column followed by water desalting, ACN elution and DESI-MS analysis, the protonated flunitrazepam $(\mathrm{m} / \mathrm{z} 314)$ was clearly detected (Figure $1 \mathrm{~b})$. Figure $1 \mathrm{~b}$ inset displays the extracted ion chromatogram (EIC) of the ion $\mathrm{m} / \mathrm{z} 314$ that shows the peak width of flunitrazepam to be 0.6 min with an average intensity of 2.95 E6 (arbitrary manufacturer unit); the entire elution process took less than 6 min. Upon CID of the $\mathrm{m} / \mathrm{z} 314$ ion, fragments were detected at $\mathrm{m} / z 268$ and $\mathrm{m} / \mathrm{z} 286$ from losses of $\mathrm{NO}_{2}$ and $\mathrm{CO}$, respectively, which is in agreement with previous reports $(30,37)$ and confirms the ion assignment. In Figure 1b, with the "desalting" and enrichment steps, aspartame was largely removed, probably due to its high solubility in water. In addition, the successful detection of $50 \mathrm{nM}$ flunitrazepam in human serum was also carried out by DESI-MS after trap column enrichment (Figure 1S, Supporting information). This result shows that trap column/DESI-MS can be used for trace analysis due to the added capabilities for desalting and enrichment. It also provides an additional example of combining fast DESI-MS analysis with various enrichment methods including microextraction (28) (38) and solid phase extraction (SPE) (39) (40).

3.1.2 Detection of proteins/peptides in phosphate buffer 
Phosphate buffer is known to have a strong suppression of MS signal. In this study, proteins/peptides in phosphate buffer such as angiotensin II and insulin were also tested using the trap column/DESI-MS apparatus.
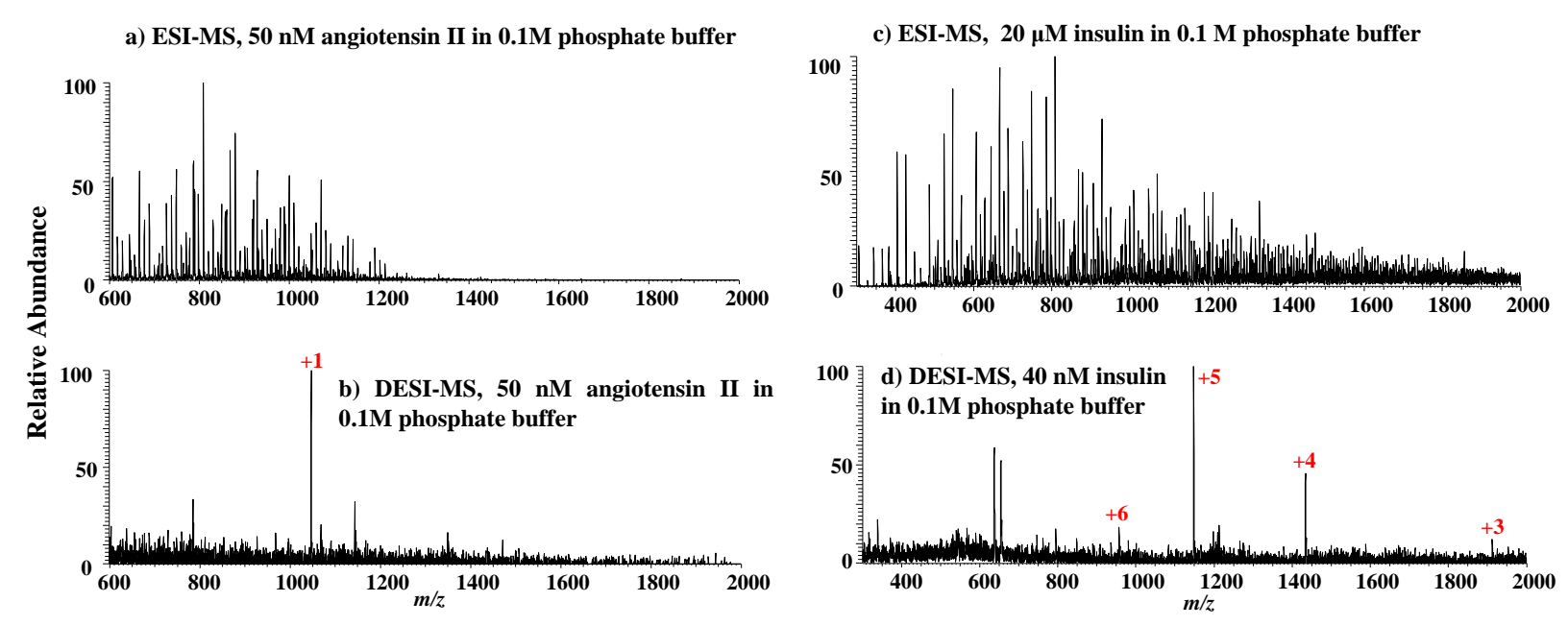

Figure 2. ESI-MS spectra of a) $50 \mathrm{nM}$ angiotensin II in $0.1 \mathrm{M}$ phosphate buffer and b) DESI-MS spectrum of $50 \mathrm{nM}$ in angiotensin II in $0.1 \mathrm{M}$ phosphate after online desalting using the trap column. ESI-MS spectra of c) $20 \mu \mathrm{M}$ insulin in $0.1 \mathrm{M}$ phosphate buffer and d) DESI-MS spectrum of $40 \mathrm{nM}$ insulin in $0.1 \mathrm{M}$ phosphate after online desalting using the trap column.

Figure 2a shows ESI-MS spectrum of $50 \mathrm{nM}$ angiotensin II in $0.1 \mathrm{M}$ phosphate buffer. No ions from the peptide were detected; rather, intense background peaks from phosphate buffer appeared. In stark contrast, Figure $2 \mathrm{~b}$ shows the DESI-MS result from $5 \mathrm{~mL}$ of $50 \mathrm{nM}$ angiotensin II in $0.1 \mathrm{M}$ phosphate buffer after the pre-concentration and online desalting using a C18 trap column; the +1 charged molecule of angiotensin II is clearly seen. In addition, the limit of detection (LOD) for angiotensin in $0.1 \mathrm{M}$ phosphate buffer is as low as $1 \mathrm{nM}$ for $5 \mathrm{~mL}$ of sample injection, using selected ion monitoring (SIM) mode. Again, this result strongly shows the power of liquid sample DESI-MS coupled with a trap cartridge column for trace analysis. 
Furthermore, by using the same column, an enrichment of a protein digest sample was achieved. $2 \mu \mathrm{g} / \mathrm{mL}$ ubiquitin was digested by trypsin in a Tris- $\mathrm{HCl}$ buffer ( $\mathrm{pH} 8$ ). Due to the strong suppression effect by Tris buffer, the digested protein could not be analyzed directly by ESI-MS without extensive desalting (data not shown). In the DESI-MS experiment, a $50 \mu \mathrm{L}$ volume of $2 \mu \mathrm{g} / \mathrm{mL}$ tryptic digested ubiquitin was introduced to the same trap column, which was subsequently washed using $200 \mu \mathrm{L}$ of water for removing Tris buffer salts. Finally a $70 \%$ ACN solvent was used to elute the peptides out. From the acquired DESI-MS spectrum (Figure $2 \mathrm{~S}$, Supporting Information), it is clearly seen that several peptide ions were detected, including $\left[\right.$ EGIPPDQQR $+2 \mathrm{H}^{2+}(\mathrm{m} / \mathrm{z}, 521),[\mathrm{ESTLHLVLR}+2 \mathrm{H}]^{2+}\left(\mathrm{m} / \mathrm{z}\right.$ 535), $[\mathrm{LIFAGK}+\mathrm{H}]^{+}(\mathrm{m} / \mathrm{z}, 649)$,

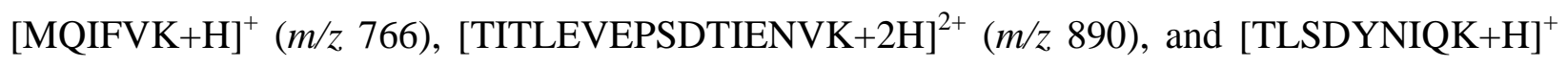
( $\mathrm{m} / \mathrm{z}$ 1083), which led to $73 \%$ sequence coverage of the protein (if excluding ions representing partially digested protein).

A rough separation of peptides is also possible with the C18 trap column. As a demonstration, a peptide mixture of Tyr-Tyr-Tyr, angiotensin II and bradykinin (50 nM each) in $0.1 \mathrm{M}$ phosphate buffer was used as a test sample. $10 \mathrm{~mL}$ of the mixture sample solution was introduced to the C18 trap column and eluted with an elution gradient program (10\% $\mathrm{ACN}$ increased to $17 \%$ in $10 \mathrm{~min}$ at a flow rate $20 \mu \mathrm{L} / \mathrm{min}$ ). Indeed, the separation of three peptides was achieved in less than $10 \mathrm{~min}$, as shown in the extracted ion chromatogram (EIC, Figure 3S, Supporting Information). Also, in this case, the DESI spray solvent was chosen to be $\mathrm{MeOH} / \mathrm{H}_{2} \mathrm{O} / \mathrm{HOAc}$ (50/50/1, by volume), which favored the ionization of the separated peptides (as the elution solvent was not acidified).

In this trap column/DESI-MS experiment, the packing material of trap column could vary. The method is also applicable for protein analysis with the use of a $\mathrm{C} 4$ trap column. In a separate 
experiment, a sample of $40 \mathrm{nM}$ insulin in $0.1 \mathrm{M}$ phosphate buffer was tested. Figure 2c shows an ESI-MS spectrum of $40 \mathrm{nM}$ insulin in $0.1 \mathrm{M}$ phosphate buffer solution. The peaks appearing in the spectrum dominantly were the salt-adducted ions, and no protein was detected. Figure $2 \mathrm{~d}$ shows the DESI-MS spectrum of $40 \mathrm{nM}$ insulin in $0.1 \mathrm{M}$ phosphate buffer after online desalting and enrichment using a C4 trap column. Clearly, $\mathrm{m} / \mathrm{z}$ 956, $\mathrm{m} / \mathrm{z}$ 1148, $\mathrm{m} / \mathrm{z} 1434$ and $\mathrm{m} / \mathrm{z}$ 1911, corresponding to $+6,+5,+4$, and +3 ions of insulin, respectively, were observed (Figure $2 \mathrm{~d}$ ), emphasizing the success of protein pre-concentration, desalting and detection in this experiment.

\subsection{Liquid DESI-MS using an enzyme-immobilized capillary column}

The identification of expressed protein components is critical in proteomics research. Traditional bottom-up approaches often employ in-solution digestion. However solution-based protein digestion has some drawbacks. The standard protocol for trypsin in-solution digestion normally needs overnight incubation that is time-consuming. In order to accelerate the digestion efficiency and reduce digestion time, increasing the concentration of enzyme could be considered. However, high concentration of trypsin could lead to autodigestion that interferes with target protein analysis (41). To achieve a high digestion efficiency within a short digestion time, several alternative approaches have been developed, including ultrasound-, high pressure-, infrared- and microwave-assisted digestions (42-46), as well as on-column digestion using immobilized enzyme $(47,48)$. The latter strategy is particularly interesting because it can be performed online with MS. However, because the buffer used for digestion may not be compatible with MS detection conditions, the digested protein solution may need additional solvent or $\mathrm{pH}$ adjustment prior to MS analysis. It would be ideal to design a method that allows direct analysis of digested proteins without additional offline sample treatment. Interestingly, liquid DESI can be used for this purpose and the underlying rationale is that the spray solvent in 
liquid DESI can be adjusted to obtain optimal ionization efficiency of the on-column digested proteins.

In this study, a trypsin-immobilized capillary column was first prepared and two proteins, $\beta$-casein and myoglobin, were chosen as test samples for demonstrating the feasibility of the combined on-column protein digestion with online DESI-MS detection for shotgun protein analysis. Protein samples are dissolved in ammonium bicarbonate buffer, an optimal solvent for trypsin digestion. This digestion buffer $\mathrm{pH}$ was kept at 8.0 to maintain trypsin activity. While a protein sample is flowed through the trypsin-immobilized column, the digestion takes place. The digested protein is subjected to DESI-MS detection while exiting the capillary column.

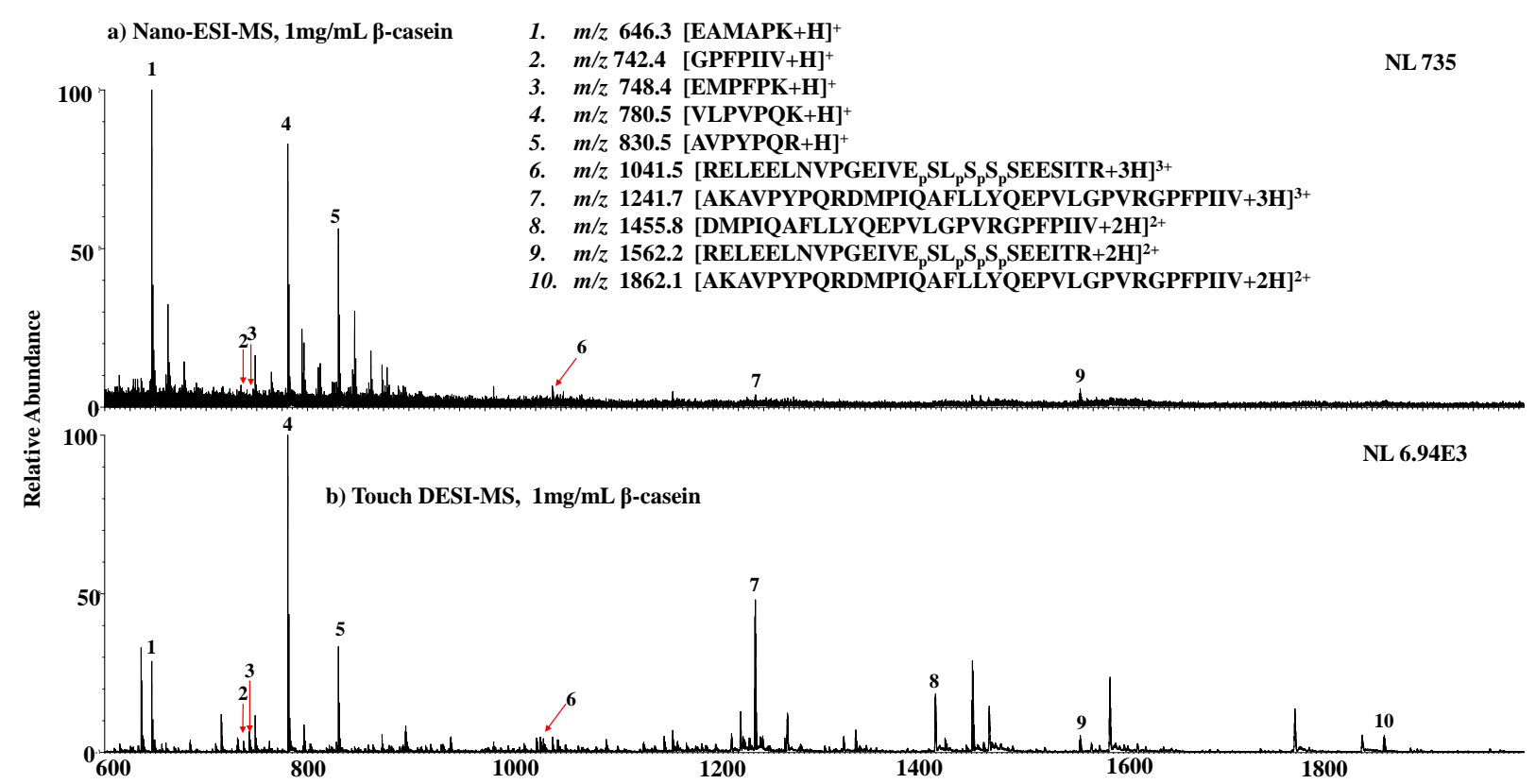

Figure 3 a) Nano ESI-MS spectrum of $1 \mathrm{mg} / \mathrm{mL} \beta$-casein in $25 \mathrm{mM}$ ammonium bicarbonate infused through the immobilized trypsin column for digestion; b) liquid DESI-MS spectrum of 1 $\mathrm{mg} / \mathrm{mL} \beta$-casein in $25 \mathrm{mM}$ ammonium bicarbonate infused through the immobilized trypsin column for digestion.

The phosphoprotein $\beta$-casein, an important component in milk, was first tested. $1 \mathrm{mg} / \mathrm{mL}$ $\beta$-casein in $25 \mathrm{mM}$ ammonium bicarbonate was infused through the capillary column for digestion. After infusion of the sample, the digested peptides could be detected by DESI-MS as 
soon as they flowed out of the column. As shown in the DESI-MS spectrum (Figure 3b), ten peptide ions including [EAMAPK $+\mathrm{H}]^{+}\left(\mathrm{m} / \mathrm{z}\right.$ 646.3), $[\mathrm{GPFPIIV}+\mathrm{H}]^{+}\left(\mathrm{m} / \mathrm{z}\right.$ 742.4), $[\mathrm{EMPFPK}+\mathrm{H}]^{+}$

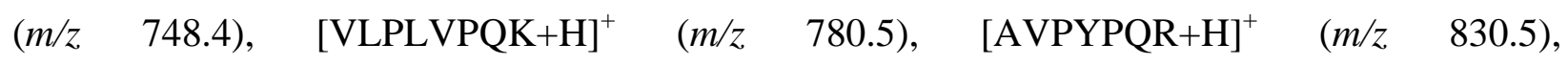
$\left[\text { RELEELNVPGEIVR }_{\mathrm{p}} \mathrm{SL}_{\mathrm{p}} \mathrm{S}_{\mathrm{p}} \mathrm{S}_{\mathrm{p}} \mathrm{SEESITR+3H}\right]^{3+} \quad(\mathrm{m} / \mathrm{z} \quad 1041.5)$, [AKAVPYPQRDMPIQAFLLYQEPVLGPVRGPFPIIV+3H] ${ }^{3+} \quad(\mathrm{m} / \mathrm{z} \quad 1241.7)$, $[\text { DMPIQAFLLYQEPVLGPVRGPFPIIV+2H] }]^{2+} \quad(m / z \quad 1455.8)$, $[\text { RELEELNVPGEIVRpSLpSpSpSEESITR+2H }]^{2+} \quad(m / z \quad 1562.2) \quad$ and [AKAVPYPQRDMPIQAFLLYQEPVLGPVRGPFPIIV+2H] ${ }^{2+} \quad(m / z, 1862.1)$ were observed. CID was used for their sequence confirmation. For example, upon CID, the phosphopeptide ion $\left[\text { RELEELNVPGEIVR } \mathrm{p}_{\mathrm{p}} \mathrm{SL}_{\mathrm{p}} \mathrm{S}_{\mathrm{p}} \mathrm{SEESITR+3H}\right]^{3+}$ at $\mathrm{m} / \mathrm{z} 1041.5$ dissociated to $\mathrm{m} / \mathrm{z} 1009.2, \mathrm{~m} / z$ 976.5, and $\mathrm{m} / \mathrm{z} 943.8$ products from losses of one, two, and three phosphate groups, respectively. Other fragment ions including $y_{1}, y_{2}, y_{3}, b_{3}, b_{4}, b_{5}, b_{6}, b_{7},\left(b_{7}\right)^{2+}, b_{8}, b_{9}, b_{10}, b_{11},\left(b_{11}\right)^{2+}, b_{12},\left(b_{12}\right)^{2+}$, $b_{13},\left(b_{13}\right)^{2+}, b_{14}$, and $\left(b_{14}\right)^{2+}$ from CID of $\mathrm{m} / \mathrm{z} 1041.5$ were also observed, confirming the ion assignment. As a comparison, nano-ESI was performed with a high voltage of $5 \mathrm{kV}$ applied directly applied to the capillary column to effect nanoelectrospray (apparatus shown in Scheme 1S, Supporting Information). However, with nano-ESI-MS, fewer peptides ions were seen and [DMPIQAFLLYQEPVLGPVRGPFPIIV+2H $]^{2+} \quad(m / z \quad 1455.8) \quad$ and [AKAVPYPQRDMPIQAFLLYQEPVLGPVRGPFPIIV+2H] ${ }^{2+} \quad(\mathrm{m} / \mathrm{z} \quad 1862.1)$ ions were not detected (Figure 3a). Besides, the absolute intensity of the base peak was 735 (manufacturer arbitrary unit, Figure 3a), which is much lower than that in the DESI-MS spectrum (6940, Figure 3b). This can be accounted for by the fact that the DESI spray solvent was $\mathrm{ACN} / \mathrm{H}_{2} \mathrm{O} / 5 \% \mathrm{FA}$ that favored peptide ionization while, in the nano-ESI, the spray solvent was $25 \mathrm{mM}$ ammonium bicarbonate and lacked organic solvent and acid additives. In addition, the entire digestion time 
took place in ca. 6 minutes (based on the flow rate of sample injection and the capillary dead volume) and direct online digestion/DESI-MS was realized, providing a fast shotgun protein analysis approach.

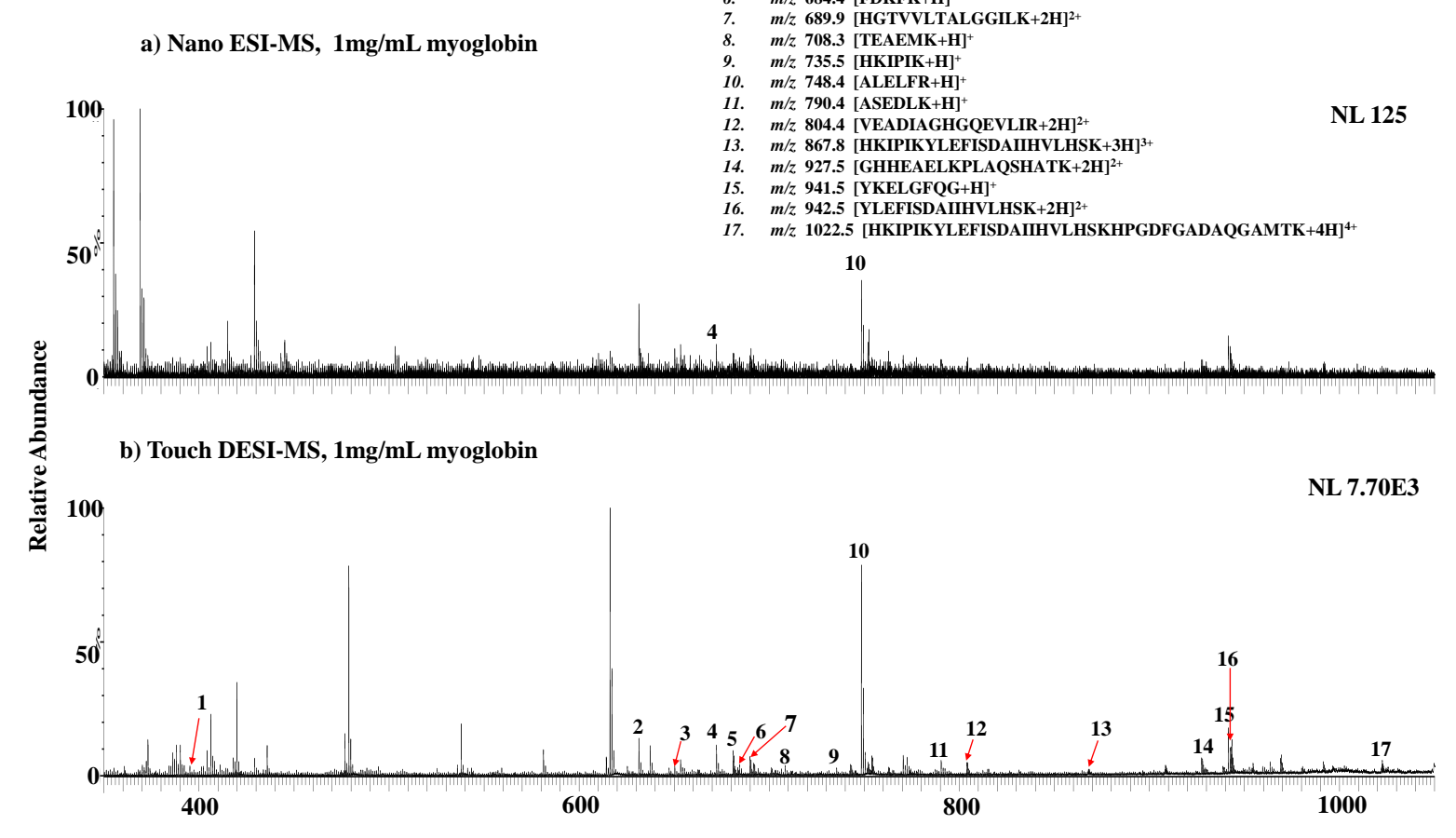

Figure 4 a) Nano ESI-MS spectrum of $1 \mathrm{mg} / \mathrm{mL}$ myoglobin in $25 \mathrm{mM}$ ammonium bicarbonate infused through the immobilized trypsin column for digestion; b) liquid DESI-MS spectrum of 1 $\mathrm{mg} / \mathrm{mL}$ myoglobin in $25 \mathrm{mM}$ ammonium bicarbonate infused through the immobilized trypsin column for digestion

Another protein test sample myoglobin was also examined. Myoglobin, known as a protease-resistant-protein, is more difficult to digest $(49,50)$. An on-column tryptic digestion was also performed with the use of the same capillary column mentioned above. A $1 \mathrm{mg} / \mathrm{mL}$ myoglobin in ammonium bicarbonate was first heated to $95^{\circ} \mathrm{C}$ for five minutes for denaturation and then was injected into the trypsin column after cooling. Figure 4 shows the contrast of the digestion results of myoglobin using nano-ESI-MS (Figure 4a) and DESI-MS (Figure 4b). With 
nano-ESI-MS, few peptide ions such as $[\mathrm{FKHLK}+\mathrm{H}]^{+}(\mathrm{m} / \mathrm{z}, 672.3)$ and $[\mathrm{ALELFR}+\mathrm{H}]^{+}(\mathrm{m} / \mathrm{z}, 748.4)$ were detected and the sequence coverage was only $6 \%$. This may be due to the ionization problem due to the digestion buffer and non-optimal nano-ESI solvent, as mentioned above. Under the same digest conditions, when the DESI was applied, many more peptide ions were seen (Figure 4b), including $[\mathrm{HLK}+\mathrm{H}]^{+}(\mathrm{m} / \mathrm{z} \text { 397.3), [NDIAAK+H}]^{+}(\mathrm{m} / z \text { 631.4), [ELGFQG+H }]^{+}$ $(m / z, 650.3),[\mathrm{FKHLK}+\mathrm{H}]^{+}(\mathrm{m} / \mathrm{z} 672.3)$, ALELFRNDIAAK $\left.+2 \mathrm{H}\right]^{2+}(\mathrm{m} / \mathrm{z} 680.9),[\mathrm{FDKFK}+\mathrm{H}]^{+}$ $(m / z \quad 684.4), \quad$ HGTVVLTALGGILK+2H $]^{2+} \quad(m / z \quad 689.9), \quad\left[\begin{array}{llll}\text { TEAEMK }+H\end{array}\right]^{+} \quad(m / z \quad 708.3)$,

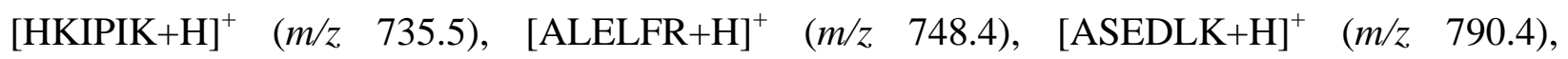
[VEADIAGHGQEVLIR+2H $^{2+} \quad(m / z, 804.4), \quad$ [HKIPIKYLEFISDAIIHVLHSK $\left.+3 \mathrm{H}^{3+}\right]^{3+}(\mathrm{m} / \mathrm{z}$ 867.8), $\quad[\text { GHHEAELKPLAQSHATK }+2 \mathrm{H}]^{2+} \quad(\mathrm{m} / \mathrm{z} \quad 927.5), \quad[\mathrm{YKELGFQG+H}]^{+} \quad(\mathrm{m} / \mathrm{z} \quad 941.5)$, $[\text { YLEFISDAIIHVLHSK }+2 \mathrm{H}]^{2+} \quad(\mathrm{m} / z \quad 942.5) \quad$ and [HKIPIKYLEFISDAIIHVLHSKHPGDFGADAQGAMTK+4H] ${ }^{4+}(\mathrm{m} / \mathrm{z} \quad 1022.5)$, showing a protein sequence coverage of $81.2 \%$. The absolute intensity of the base peak in the DESI-MS spectrum (7700) is more than 60 times higher than that of nano-ESI-MS spectrum (125). This result further suggests the advantage of coupling an enzyme-immobilized capillary column with DESI-MS detection for protein analysis, providing both high sensitivity and fast analysis.

In this experiment, our modified DESI is similar to ESI with use of a sheath liquid (51) in terms of ion source configuration. However, they are different and there are several advantages with our modified DESI method that are important for fast analysis in comparison to ESI. First, both tips of the two capillaries were tapered to achieve the nanoelectrospray effect for enhancing ionization sensitivity, which is not possible for the two capillaries used in ESI that are concentric. In addition, it is very easy to install/uninstall the whole apparatus in our modified liquid DESI setup, which only needs the two capillary tips to be in contact with each other. Third, the sample 
capillary in our DESI method is easily replaced and modified, which is essential for enzymeimmobilization.

\section{Conclusions}

In conclusion, enhanced performance of liquid sample DESI-MS were achieved using trap cartridge columns or enzyme-bound capillary columns. In combination using a trap column for desalting and enrichment of low concentration samples, trace amount (nM concentration) of drug-of-abuse in drink or peptides or proteins in nonvolatile phosphate buffer can be detected with DESI-MS. In addition, DESI-MS coupled with a modified capillary column is capable of performing fast on-column trypsin digestion of myoglobin and phosphoprotein $\beta$-casein with high sensitivity and analysis speed. It is expected that this modified DESI-MS method would have great potential applications in both trace analysis and proteomics research.

\section{Acknowledgements}

This work was supported by NSF Career Award (CHE-1149367), NSF (CHE-1455554), and NNSFC (21328502). JAL acknowledges support from the National Institutes of Health (R01GM103479).

\section{References}

1. Takáts Z, Wiseman JM, Gologan B, Cooks RG. Mass Spectrometry Sampling Under Ambient Conditions with Desorption Electrospray Ionization. Science. 2004 October 15, 2004;306(5695):471-3. 
2. Wiseman JM, Ifa DR, Zhu Y, Kissinger CB, Manicke NE, Kissinger PT, et al. Desorption electrospray ionization mass spectrometry: Imaging drugs and metabolites in tissues. Proceedings of the National Academy of Sciences. 2008 November 25, 2008;105(47):18120-5.

3. Cotte-Rodríguez I, Mulligan CC, Cooks RG. Non-Proximate Detection of Small and Large Molecules by Desorption Electrospray Ionization and Desorption Atmospheric Pressure Chemical Ionization Mass Spectrometry: Instrumentation and Applications in Forensics, Chemistry, and Biology. Analytical Chemistry. 2007 2007/09/01;79(18):7069-77.

4. Pan Z, Gu H, Talaty N, Chen H, Shanaiah N, Hainline B, et al. Principal component analysis of urine metabolites detected by NMR and DESI-MS in patients with inborn errors of metabolism. Analytical and Bioanalytical Chemistry. 2007 2007/01/01;387(2):539-49. English.

5. Kauppila TJ, Talaty N, Kuuranne T, Kotiaho T, Kostiainen R, Cooks RG. Rapid analysis of metabolites and drugs of abuse from urine samples by desorption electrospray ionization-mass spectrometry. Analyst. 2007;132(9):868-75.

6. Morelato M, Beavis A, Kirkbride P, Roux C. Forensic applications of desorption electrospray ionisation mass spectrometry (DESI-MS). Forensic Science International. 2013;226(1-3):10-21.

7. Suni NM, Lindfors P, Laine O, Östman P, Ojanperä I, Kotiaho T, et al. Matrix effect in the analysis of drugs of abuse from urine with desorption atmospheric pressure photoionization-mass spectrometry (DAPPI-MS) and desorption electrospray ionizationmass spectrometry (DESI-MS). Analytica Chimica Acta. 2011;699(1):73-80. 
8. Sanders NL, Kothari S, Huang G, Salazar G, Cooks RG. Detection of Explosives as Negative Ions Directly from Surfaces Using a Miniature Mass Spectrometer. Analytical Chemistry. 2010 2010/06/15;82(12):5313-6.

9. Wells JM, Roth MJ, Keil AD, Grossenbacher JW, Justes DR, Patterson GE, et al. Implementation of DART and DESI Ionization on a Fieldable Mass Spectrometer. Journal of the American Society for Mass Spectrometry. 2008;19(10):1419-24.

10. D'Agostino PA, Chenier CL. Desorption electrospray ionization mass spectrometric analysis of organophosphorus chemical warfare agents using ion mobility and tandem mass spectrometry. Rapid Communications in Mass Spectrometry. 2010;24(11):1617-24.

11. Douglass KA, Venter AR. Protein analysis by desorption electrospray ionization mass spectrometry and related methods. Journal of Mass Spectrometry. 2013;48(5):553-60.

12. Miao Z, Chen H. Direct Analysis of Liquid Samples by Desorption Electrospray Ionization-Mass Spectrometry (DESI-MS). Journal of the American Society for Mass Spectrometry. 2009;20(1):10-9.

13. Ma X, Zhao M, Lin Z, Zhang S, Yang C, Zhang X. Versatile Platform Employing Desorption Electrospray Ionization Mass Spectrometry for High-Throughput Analysis. Analytical Chemistry. 2008 2008/08/01;80(15):6131-6.

14. Chipuk JE, Brodbelt JS. Transmission Mode Desorption Electrospray Ionization. Journal of the American Society for Mass Spectrometry. 2008;19(11):1612-20.

15. Moore BN, Hamdy O, Julian RR. Protein structure evolution in liquid DESI as revealed by selective noncovalent adduct protein probing. International journal of mass spectrometry. 2012;330-332:220-5. PubMed PMID: PMC3601934. 
16. Miao Z, Chen, H. . Proceedings of 56th ASMS Conference on Mass and Allied Topics. Denver, CO, June1-5 2008. 2008. English.

17. Miao Z, Wu S, Chen H. The Study of Protein Conformation in Solution Via Direct Sampling by Desorption Electrospray Ionization Mass Spectrometry. Journal of the American Society for Mass Spectrometry. 2010;21(10):1730-6. PubMed PMID: PMC3704159.

18. Pan N, Liu P, Cui W, Tang B, Shi J, Chen H. Highly efficient ionization of phosphopeptides at low $\mathrm{pH}$ by desorption electrospray ionization mass spectrometry. Analyst. 2013;138(5):1321-4.

19. Ferguson CN, Benchaar SA, Miao Z, Loo JA, Chen H. Direct Ionization of Large Proteins and Protein Complexes by Desorption Electrospray Ionization-Mass Spectrometry. Analytical Chemistry. 2011 2011/09/01;83(17):6468-73.

20. Yao Y, Shams-Ud-Doha K, Daneshfar R, Kitova E, Klassen J. Quantifying ProteinCarbohydrate Interactions Using Liquid Sample Desorption Electrospray Ionization Mass Spectrometry. Journal of The American Society for Mass Spectrometry. 2015 2015/01/01;26(1):98-106. English.

21. Liu P, Zhang J, Ferguson CN, Chen H, Loo JA. Measuring Protein-Ligand Interactions Using Liquid Sample Desorption Electrospray Ionization Mass Spectrometry. Analytical Chemistry. 2013 2013/12/17;85(24):11966-72.

22. Zhang Y, Chen H. Detection of saccharides by reactive desorption electrospray ionization (DESI) using modified phenylboronic acids. International Journal of Mass Spectrometry. 2010;289(2-3):98-107. 
23. Miao Z, Chen H, Liu P, Liu Y. Development of Submillisecond Time-Resolved Mass Spectrometry Using Desorption Electrospray Ionization. Analytical Chemistry. 2011 2011/06/01;83(11):3994-7.

24. Zhang Y, Dewald HD, Chen H. Online Mass Spectrometric Analysis of Proteins/Peptides Following Electrolytic Cleavage of Disulfide Bonds. Journal of Proteome Research. 2011 2011/03/04;10(3):1293-304.

25. Liu Y, Miao Z, Lakshmanan R, Loo RRO, Loo JA, Chen H. Signal and charge enhancement for protein analysis by liquid chromatography-mass spectrometry with desorption electrospray ionization. International Journal of Mass Spectrometry. 2012;325327(0):161-6.

26. Cai Y, Adams D, Chen H. A New Splitting Method for Both Analytical and Preparative LC/MS. Journal of The American Society for Mass Spectrometry. 2014 2014/02/01;25(2):286-92. English.

27. Cai Y, Liu Y, Helmy R, Chen H. Coupling of Ultrafast LC with Mass Spectrometry by DESI. Journal of The American Society for Mass Spectrometry. 2014 2014/10/01;25(10):1820-3. English.

28. Sun X, Miao Z, Yuan Z, Harrington PdB, Colla J, Chen H. Coupling of single droplet micro-extraction with desorption electrospray ionization-mass spectrometry. International Journal of Mass Spectrometry. 2011;301(1-3):102-8.

29. Li J, Dewald HD, Chen H. Online Coupling of Electrochemical Reactions with Liquid Sample Desorption Electrospray Ionization-Mass Spectrometry. Analytical Chemistry. 2009 2009/12/01;81(23):9716-22. 
30. Lu M, Wolff C, Cui W, Chen H. Investigation of some biologically relevant redox reactions using electrochemical mass spectrometry interfaced by desorption electrospray ionization. Analytical and bioanalytical chemistry. 2012;403(2):355-65. PubMed PMID: PMC3731448.

31. Brown TA, Chen H, Zare RN. Identification of Fleeting Electrochemical Reaction Intermediates Using Desorption Electrospray Ionization Mass Spectrometry. Journal of the American Chemical Society. 2015 2015/06/17;137(23):7274-7.

32. Brown TA, Chen H, Zare RN. Detection of the Short-Lived Radical Cation Intermediate in the Electrooxidation of N,N-Dimethylaniline by Mass Spectrometry. Angewandte Chemie. 2015:n/a-n/a.

33. Zhang Y, Cui W, Zhang H, Dewald HD, Chen H. Electrochemistry-Assisted Top-Down Characterization of Disulfide-Containing Proteins. Analytical chemistry. 2012;84(8):383842. PubMed PMID: PMC3661022.

34. Zheng Q, Zhang $\mathrm{H}$, Chen $\mathrm{H}$. Integration of online digestion and electrolytic reduction with mass spectrometry for rapid disulfide-containing protein structural analysis. International journal of mass spectrometry. 2013;353:84-92. PubMed PMID: PMC4240030.

35. Zheng Q, Zhang H, Tong L, Wu S, Chen H. Cross-Linking Electrochemical Mass Spectrometry for Probing Protein Three-Dimensional Structures. Analytical Chemistry. 2014 2014/09/16;86(18):8983-91.

36. Sproß J, Sinz A. A Capillary Monolithic Trypsin Reactor for Efficient Protein Digestion in Online and Offline Coupling to ESI and MALDI Mass Spectrometry. Analytical Chemistry. 2010 2010/02/15;82(4):1434-43. 
37. D'Aloise P, Chen H. Rapid determination of flunitrazepam in alcoholic beverages by desorption electrospray ionization-mass spectrometry. Science \& Justice. 2012;52(1):2-8.

38. Strittmatter N, During R-A, Takats Z. Analysis of wastewater samples by direct combination of thin-film microextraction and desorption electrospray ionization mass spectrometry. Analyst. 2012;137(17):4037-44.

39. Dénes Jl, Katona Mr, Hosszú Adm, Czuczy Nm, Takáts Zn. Analysis of Biological Fluids by Direct Combination of Solid Phase Extraction and Desorption Electrospray Ionization Mass Spectrometry. Analytical Chemistry. 2009 2009/02/15;81(4):1669-75.

40. Kennedy JH, Aurand C, Shirey R, Laughlin BC, Wiseman JM. Coupling Desorption Electrospray Ionization with Solid-Phase Microextraction for Screening and Quantitative Analysis of Drugs in Urine. Analytical Chemistry. 2010 2010/09/01;82(17):7502-8.

41. Zhang K, Wu S, Tang X, Kaiser NK, Bruce JE. A bifunctional monolithic column for combined protein preconcentration and digestion for high throughput proteomics research. Journal of Chromatography B. 2007;849(1-2):223-30.

42. Wang S, Bao H, Liu T, Zhang L, Yang P, Chen G. Accelerated proteolysis in alternating electric fields for peptide mapping. Rapid Communications in Mass Spectrometry. 2008;22(20):3225-32.

43. Basile F, Zhang S, Kandar SK, Lu L. Mass Spectrometry Characterization of the Thermal Decomposition/Digestion (TDD) at Cysteine in Peptides and Proteins in the Condensed Phase. Journal of the American Society for Mass Spectrometry. 2011;22(11):1926-40. PubMed PMID: PMC3195377. 
44. Hauser NJ, Basile F, Han H, McLuckey SA. Electron Transfer Dissociation of Peptides Generated by Microwave D-Cleavage Digestion of Proteins. Journal of proteome research. 2008;7(5):1867-72. PubMed PMID: PMC2707827.

45. Bao H, Lui T, Zhang L, Chen G. Infrared-assisted proteolysis using trypsin-immobilized silica microspheres for peptide mapping. PROTEOMICS. 2009;9(4):1114-7.

46. Dycka F, Bobal P, Mazanec K, Bobalova J. Rapid and efficient protein enzymatic digestion: An experimental comparison. ELECTROPHORESIS. 2012;33(2):288-95.

47. Ye M, Hu S, Schoenherr RM, Dovichi NJ. On-line protein digestion and peptide mapping by capillary electrophoresis with post-column labeling for laser-induced fluorescence detection. ELECTROPHORESIS. 2004;25(9):1319-26.

48. Peterson DS, Rohr T, Svec F, Fréchet JMJ. High-Throughput Peptide Mass Mapping Using a Microdevice Containing Trypsin Immobilized on a Porous Polymer Monolith Coupled to MALDI TOF and ESI TOF Mass Spectrometers. Journal of Proteome Research. 2002 2002/12/01;1(6):563-8.

49. Slysz GW, Schriemer DC. On-column digestion of proteins in aqueous-organic solvents. Rapid Communications in Mass Spectrometry. 2003;17(10):1044-50.

50. Reddy PM, Hsu W-Y, Hu J-F, Ho Y-P. Digestion Completeness of Microwave-Assisted and Conventional Trypsin-Catalyzed Reactions. Journal of the American Society for Mass Spectrometry. 2010;21(3):421-4.

51. Smith RD, Loo JA, Edmonds CG, Barinaga CJ, Udseth HR. New developments in biochemical mass spectrometry: electrospray ionization. Analytical Chemistry. 1990 1990/05/01;62(9):882-99. 


\section{Graphic abstract}

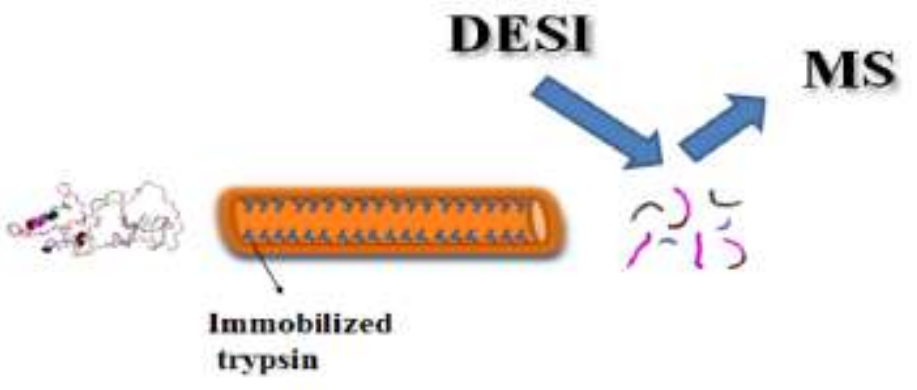

